\title{
55. MODELING OF MAGNETIC AND GRAVITY ANOMALIES AT GOBAN SPUR, NORTHEASTERN ATLANTIC 1
}

\author{
Roger A. Scrutton, Grant Institute of Geology, University of Edinburgh ${ }^{2}$
}

\begin{abstract}
Magnetic and gravity anomalies in the vicinity of the continent-ocean transition at Goban Spur have been modeled to give crustal structure and magnetization. If the location of the transition identified from seismic reflection profiles (see Masson et al., this volume) is accepted, then the magnetic anomalies together with drilling results, suggest widespread basaltic igneous activity in the continental rift zone just before and just after the onset of seafloor spreading. This spreading took place at a rate of about $5 \mathrm{~mm} / \mathrm{yr}$. for approximately the first $25 \mathrm{~m}$.y., during the long Cretaceous interval of normal polarity. Gravity modeling suggests that a continental crust 6 to $14 \mathrm{~km}$ thick occurs between Pendragon Escarpment and the transition, and that relatively less crustal thinning has occurred adjacent to the continentocean transition in the region of $48-48.5^{\circ} \mathrm{N}$ than has occurred farther north. In the same region, both magnetic and gravity data could be interpreted in terms of a continent-ocean transition located farther to the west, but there are alternative interpretations, such as the occurrence of early asymmetrical spreading or of a tongue of early Bay of Biscay ocean crust extending northward partway past Goban Spur.
\end{abstract}

\section{INTRODUCTION}

Between 1976 and 1979, the University of Edinburgh conducted three geophysical/geological cruises in the Goban Spur area of the northwestern European continental margin. Underway analog, two-channel seismic reflection, gravity, magnetic, and bathymetric data were recorded on nearly all tracks (shown in Fig. 1), and about forty dredge and soft-sediment core stations were occupied. Dredging recovered mildly metamorphosed middle Devonian sandstones from Pendragon Escarpment (Fig. 2 ); the sediment cores, up to $2 \mathrm{~m}$ in length, are still being studied for micropaleontological evidence of late glacial climatic fluctuations (R. V. Dingle, pers. comm., 1983).

The geophysical surveying was carried out on a rough grid pattern (Fig. 1) to provide good regional data coverage. Interpretations of these data have already been published by Scrutton (1979) and Dingle and Scrutton (1977, 1979). Free-air gravity and total-field magnetic anomaly data have been compiled with other data into the contour charts presented in this volume by Masson et al. The seismic reflection profiles have been used together with all other seismic profile data by the same authors to produce charts of acoustic parameters for Goban Spur. None of these compilations is presented here, and the reader is referred to Masson et al. (this volume).

This chapter concentrates on the two- and three-dimensional modeling of potential-field anomalies seen in the Edinburgh data. It accepts as a working hypothesis the location of the continent-ocean transition (COT) off Goban Spur as deduced principally from seismic reflection data by Masson et al. (this volume), and examines

\footnotetext{
${ }^{1}$ Graciansky, P. C. de, Poag, C. W., et al., Init. Repts. DSDP, 80: Washington (U.S Govt. Printing Office).

2 Address: Grant Institute of Geology, Univ. of Edinburgh, West Mains Road, Edinburgh EH9 3JW, United Kingdom.
}

the implications of this for the interpretation of the anomalies. From the gravity and magnetic data it is possible to model the position of a sharp continent-ocean "contact," but often this does not coincide exactly with the presumed continent-ocean transition, so lending support to the concept of a transition rather than a sharper boundary. Masson et al. (this volume) believe that the transition is up to $10 \mathrm{~km}$ wide. The gravity and magnetic data also supplement reflection and drilling results by providing additional evidence for (1) the age of seafloor spreading in Porcupine Abyssal Plain, (2) the extent of basaltic volcanism in the continental rift zone east of the transition, and (3) variations in crustal thickness.

Goban Spur is a three-dimensional bathymetric feature. Regional gravity modeling has therefore been carried out in three dimensions, although approximations to body shape are poorer than with two-dimensional modeling. The regional gravity profiles in Figure 2 should be considered as only approximate, but they are clearly better than two-dimensional regionals, in particular over the northern and southern parts of Goban Spur. Most local gravity anomalies and magnetic anomalies are twodimensional or nearly two-dimensional in aspect, and have been modeled accordingly.

\section{MAGNETIC MODELS}

One objective of the magnetic modeling was to establish that the ocean crust between Site 550 and the first strong magnetic anomaly to the west, the deep negative between 15 and $151 / 2^{\circ} \mathrm{W}$ (Figs. 1 and 2), belongs to the long mid-Cretaceous normal polarity epoch. This would also support the case for the deep negative being Anomaly 33-34 (Kristoffersen, 1978; Masson et al., this volume) rather than 31-32 (Srivastava, 1978). The quasilineated, low-amplitude anomalies seen between Site 550 and Anomaly ?34 would then have to be the result of topography on a normally magnetized ocean crust, possibly combined with variations in the strength of mag- 


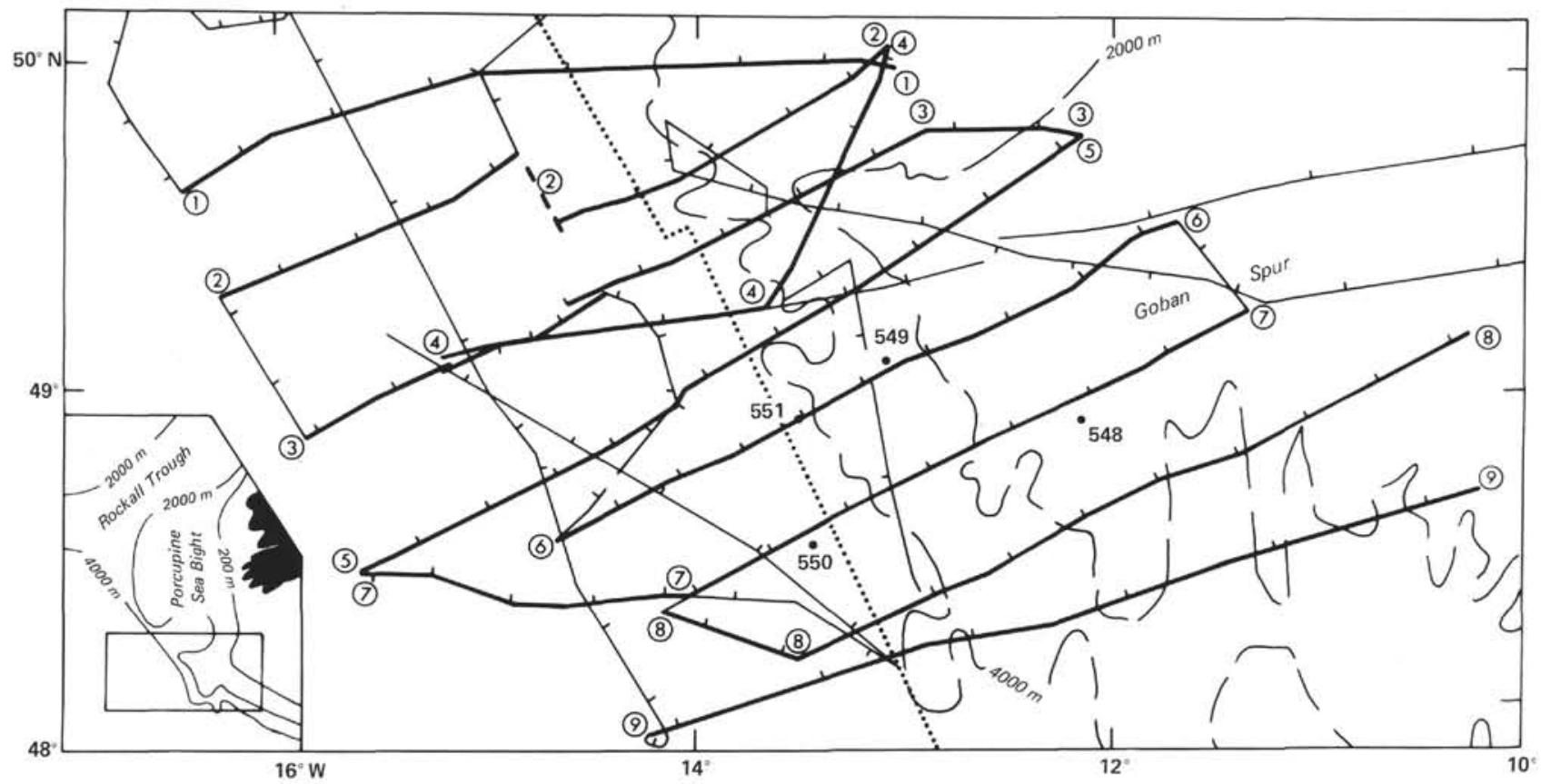

Figure 1. Track chart of University of Edinburgh data over Goban Spur (2000- and 4000-m isobaths shown). Most lines have seismic reflection, gravity, and magnetic data. Heavy lines are those presented as profiles 1 to 9 in Figure 2. The ticks on the tracks are at 3-hr. intervals, and can be keyed to Figure 2. The dotted line striking NNW is the presumed location of the continent-ocean transition, taken from the seismic reflection interpretation of Masson et al. (this volume). Inset shows position of surveyed area with respect to Ireland.

netization. It can be seen in Figure 2 that one of the strongest of these anomalies occurs at Site 550 (line 7) and to the south of it (line 8).

A detailed model of magnetization along line 7 (Fig. 3) shows that it is feasible to account for the anomalies between Site 550 and Anomaly ?33-34 with normally magnetized ocean crust. Less detailed models of lines 6 and 4 to the north and 8 to the south (discussed later in this chapter) suggest that this is so everywhere off Goban Spur. It is therefore concluded that this crust was formed in the mid-Cretaceous between early Albian (the time of the rifting-to-spreading change; Masson et al., this volume) and Santonian (Anomaly 34), at a relatively slow rate. Assuming a spreading pattern that is symmetrical with the Flemish Cap margin, and an E-W direction of spreading, the rate would be about $5 \mathrm{~mm} / \mathrm{yr}$.

An interesting feature of the models mentioned in the foregoing is the high magnetization required in the vicinity of Site 550 , up to $12 \mathrm{~A} / \mathrm{m}$ on line 7 . For ocean crust older than about 5 m.y., magnetizations of up to about $5 \mathrm{~A} / \mathrm{m}$ (normalized to the equator according to Harrison, 1981) are appropriate for a magnetized layer of 1.5 to $2 \mathrm{~km}$ thickness, as used here. A magnetization of $12 \mathrm{~A} / \mathrm{m}$ normalizes to $8.5 \mathrm{~A} / \mathrm{m}$ at the equator, and is thus very high. Perhaps the composition and structure of the ocean crust hereabouts are the causes of the high magnetization. As pointed out by Harrison (1981), the proportions and states of oxidation of massive and pillow basalts in seismic Layer 2 are relevant factors. The basalts recovered at Site 550 are remarkably unaltered pillows and flows that may be strongly magnetized.

A second objective of the modeling was to investigate further the positive anomaly, over and immediately east of the COT, that apparently reflects the presence of ba- saltic igneous rocks. The presence of these rocks was predicted by Scrutton (1979) (Fig. 4) and confirmed by drilling at Site 551, and has raised the question of precisely where a sharp continent-ocean boundary is located: at the eastern limit of clear oceanic basement on seismic records or within the zone of highly magnetic basaltic rocks.

Modeling of lines 6 (Figs. 4 and 5), 7 (Fig. 3), 4 (Fig. 6), and 1 (Fig. 7) indicates that magnetic, presumably basaltic, rocks are widespread over and to the east of the presumed COT. On line 4 they appear to continue eastward to the Pendragon Escarpment (Fig. 2). The magnetic low defining their easterly limit in this area strikes WNW-ESE, oblique to the NNW-SSE trend of the COT. Since the escarpment has the same oblique trend, it is likely that here there is an underlying structural control on the distribution of the basaltic rocks. On line $7 \mathrm{a} \mathrm{mi-}$ nor occurrence of magnetized rocks is detached from the main bulk in the vicinity of the COT, and is more readily interpreted as representing intrusives or extrusives in the continental rift zone. Clearly, if the location of the COT is correctly identified from seismic data, there was widespread basaltic igneous activity in the rift zone up to approximately $40 \mathrm{~km}$ from the locus of seafloor spreading.

Line 8 may be interpreted without including any magnetic rocks east of the presumed COT (Fig. 8). There are strong similarities, however, between the anomalies and the model of this line and those of line 4, where magnetized rocks occur well east of the COT. There are additional ambiguities over the siting of the COT on line 8 , and these are discussed in the next section.

Goban Spur itself is magnetically quiet, except in its innermost parts, where some igneous activity has prob- 
ably occurred. This emphasizes the weakly magnetic character of the Hercynian basement rocks, presumably nonmetamorphosed or mildly metamorphosed sediments with equally weakly magnetized granites (Masson et al., this volume).

\section{GRAVITY MODELS}

A comparison of free-air gravity-anomaly profiles with regional profiles calculated for a three-dimensional isostatic model of the crust reveals a number of local gravity highs and lows that may be termed isostatic anomalies $\left(\mathrm{H}_{1}, \mathrm{H}_{2}, \mathrm{~L}_{1}\right.$, and $\mathrm{L}_{2}$ on Fig. 2).

Some modeling of the gravity data has already been done (Scrutton, 1979; Fig. 4). In that modeling, high $\mathrm{H}_{1}$ on line 6 was thought to result from interbedded sedimentary and igneous rocks-together of a density equivalent to that of basement rocks, thus contrasting with low-density, wholly sedimentary rocks to the east and west-the igneous rocks being the basaltic ones of the rift zone referred to in the previous section. The high $\mathrm{H}_{1}$ can be traced northward to lines 5 and 4 , but does not appear on line 3, where the extensive presence of basaltic rocks is unlikely. It may reappear on line 2 in association with a small but prominent magnetic anomaly, and has been modeled on line 1 (Fig. 7), albeit originally as a topographic high in oceanic basement (J. B. Megson, pers. comm., 1983). Line 7 to the south does not show $\mathrm{H}_{1}$, probably because it is close to the southern limit of the basaltic rocks, where they give way to a wholly sedimentary succession overlying basement fault blocks, as seen on line 8 (Figs. 8 and 9). Thus, high $\mathrm{H}_{1}$ may reflect the distribution of rift zone igneous rocks, as does the related magnetic high.

The other prominent isostatic gravity anomaly is low $\mathrm{L}_{2}$. It replaces $\mathrm{H}_{1}$ southward, but broadens out to transgress the presumed COT location on lines 8 and 9, and surrounds gravity high $\mathrm{H}_{2}$ caused by the non-magnetic basement high of Menez Braz. It is noteworthy that the western limit of the low is coincident with the zone of strong magnetizations modeled on lines 7 and 8 . Seismic reflection data from line 8 (Fig. 9) suggest that a sediment layer slightly thicker than in surrounding areas coincides with the low, and this can account for a small part of the gravity deficit (Fig. 8). The remainder of the low could be satisfied by a substantial fall in crustal density (about $0.3 \mathrm{Mg} / \mathrm{m}^{3}$ throughout) or a crustal root or some combination of the two. For instance, low-density granite may occur in the crust together with a root. In Figure 8 it is assumed that a crustal root is the cause, since it can satisfactorily account for the gravity gradients and amplitudes with a realistic body size and density contrast. Assuming further that the COT is correctly located, the geological model is one of a depressed ocean crust bordering a depressed and relatively little-attenuated continental crust. Earlier modeling of the crust on line 6 shows, along strike, an undepressed ocean crust and a more attenuated ( $8 \mathrm{~km}$ compared with $14 \mathrm{~km})$ continental crust.

An alternative interpretation of the data on line 8 is that the COT is located farther west-beyond the edge of the thick sediments and deep Moho defined by the gravity low (Figure 8)-and coincides with the western flank of the strong positive magnetic anomaly, as it does on lines to the north. In this situation it would again be necessary that basaltic rocks be present in the rift zone to the east. Seismic reflection data on line 8 cannot resolve the problem, but from regional analysis it appears that the easterly position for the COT is the more likely one.

Gravity low $L_{1}$ has a different setting from $L_{2}$. It occurs at the foot of Pendragon Escarpment and probably contains a strong element of gravity edge effect, assuming local Airy isostasy. The three-dimensional model apparently cannot account for it, however, leaving as possible causes a thickened sediment pile, a density deficit in the crust, or a crustal root. The modeling of line 6 (Fig. 4), on which the gravity anomalies are similar, suggests that density contrasts at shallow depth are largely responsible, possibly in the form of thicker sediments underlying the basaltic igneous rocks of this area.

The gravity modeling has assumed that local Airy isostasy has prevailed at Goban Spur. However, after thinning of the continental crust during rifting, subsidence caused by thermal and sediment loading effects most probably took place by flexure (Masson et al., this volume), which produces a different regional gravity field. Regions of substantial crustal thinning or ocean crust providing potential loads border Goban Spur on all sides but the east, with Porcupine Sea Bight also being the locus of heavy post-rift sedimentation. Flexure resulting from this load distribution generates around the spur edge effects of relatively long wavelength, yet a comparison in Figure 2 of observed and calculated anomalies does not suggest that the wavelengths of the edge effects of the local Airy model are too short. Thus, since it is not evident from the data that large flexural effects have been ignored in generating a regional gravity field, it is felt that the shape and amplitude of the local isostatic highs and lows are in fact reasonably good.

\section{CONCLUSIONS AND DISCUSSION}

Most of the conclusions drawn from the modeling concern the early evolution of the North Atlantic rift at Goban Spur. The indications of basaltic igneous activity in the immediate vicinity of the ultimate continental split (Fig. 10) are not surprising, by analogy with other rift zones. However, the basalts at Site 551 are chemically typical of oceanic tholeiitic volcanism (Maury et al., this volume). The basalt flows and pillows are upper Cenomanian, but beneath there may be more basalts of greater age. Overall, there could be both intra-rift volcanics of the rifting phase and oceanic volcanics erupted over the flanks of the split at and after the onset of spreading in the Albian. One cannot distinguish between the two from the potential-field data, because of the inherent ambiguity in their interpretation. A mixture of the two types of activity is a reasonable possibility.

The geophysical data are consistent with the early seafloor spreading occurring in the Albian-Santonian period. The work of Srivastava (1978) on magnetic anomalies suggests that the spreading was probably more or less symmetrical with the Flemish Cap margin. Never- 


\section{R. A. SCRUTTON}
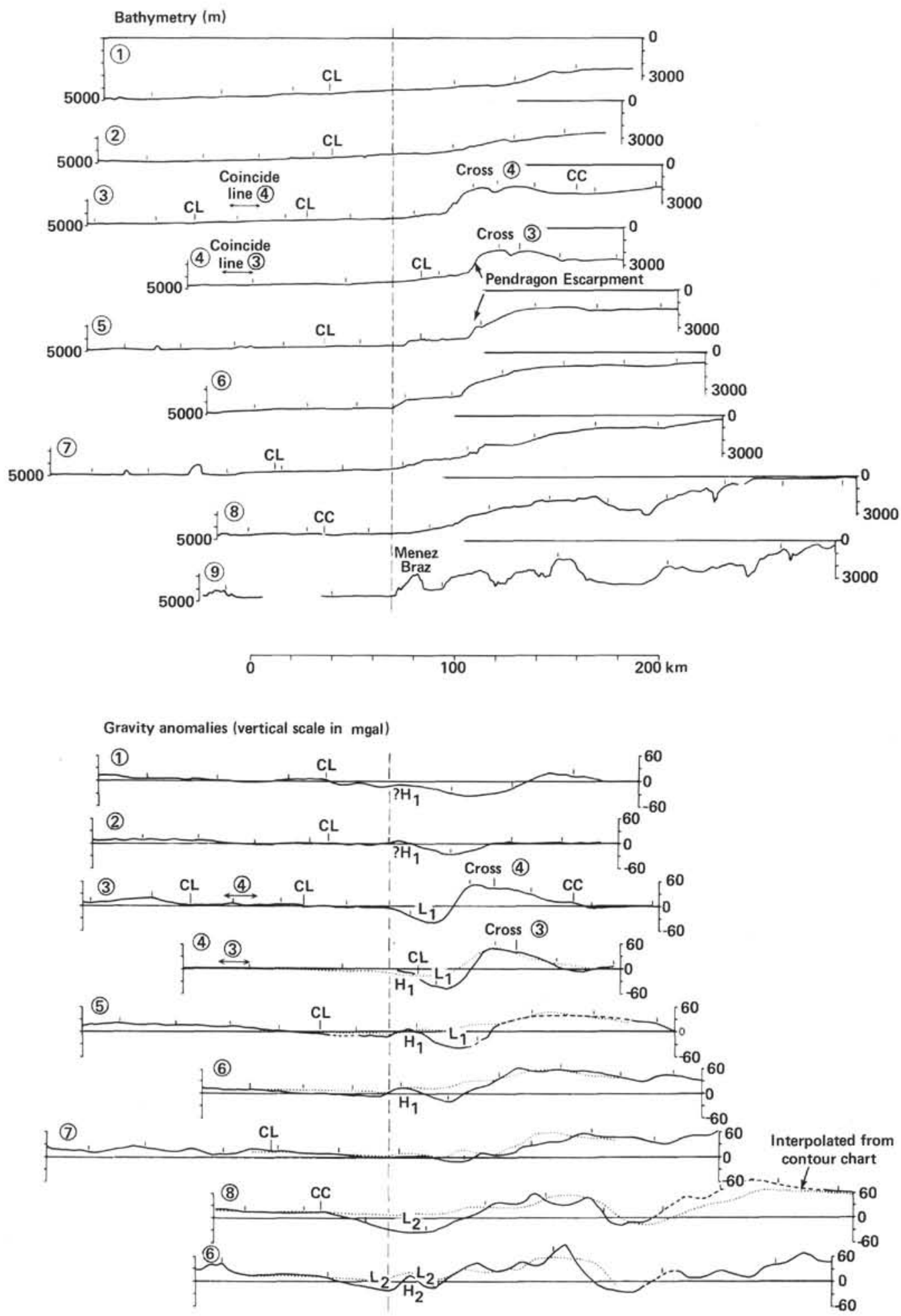

Calculated anomalies for three-dimensional isostatic model

Figure 2. Bathymetric, gravity, and magnetic profiles across the continental margin at Goban Spur. Their locations are shown in Figure 1. Some profiles are composites of different survey lines; CL indicates change of line and CC indicates a course change within a line. Three-hour ticks are given against each profile to key to Figure 1. The profiles are aligned along the presumed continent-ocean transition (Fig. 1); thus, between 2 and 3 there is a small off set. Gravity highs $\mathrm{H}_{1}$ and $\mathrm{H}_{2}$ and lows $\mathrm{L}_{1}$ and $\mathrm{L}_{2}$ are discussed in the text. The dotted gravity profiles on lines 4 to 9 were calculated for a three-dimensional isostatic model of Goban Spur (local Airy isostasy, $T=29 \mathrm{~km}, \rho_{\text {crust }}-\rho_{\text {water }}=1.64 \mathrm{Mg} / \mathrm{m}^{3}, \rho_{\text {mantle }}-\rho_{\text {crust }}=0.41 \mathrm{Mg} / \mathrm{m}^{3}$ ), but should be considered only approximate. 


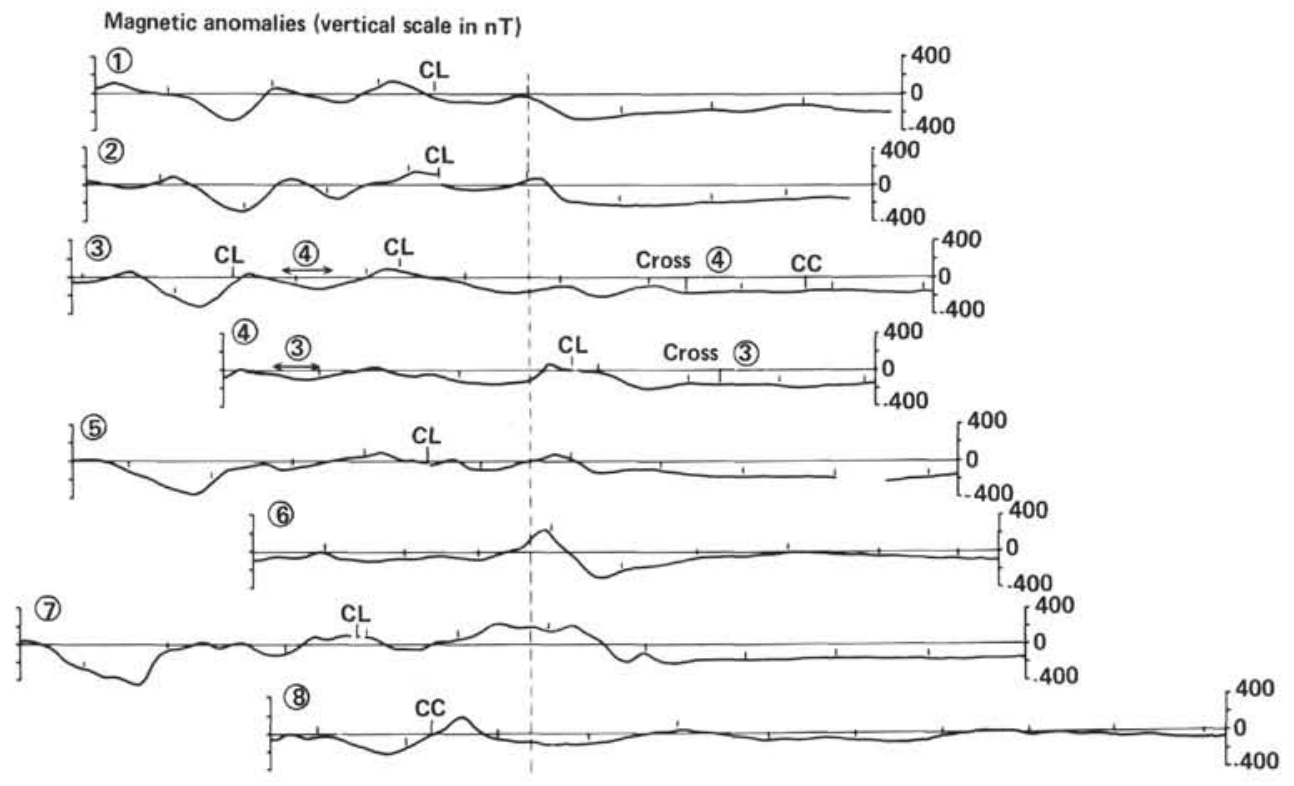

Figure 2. (Continued).

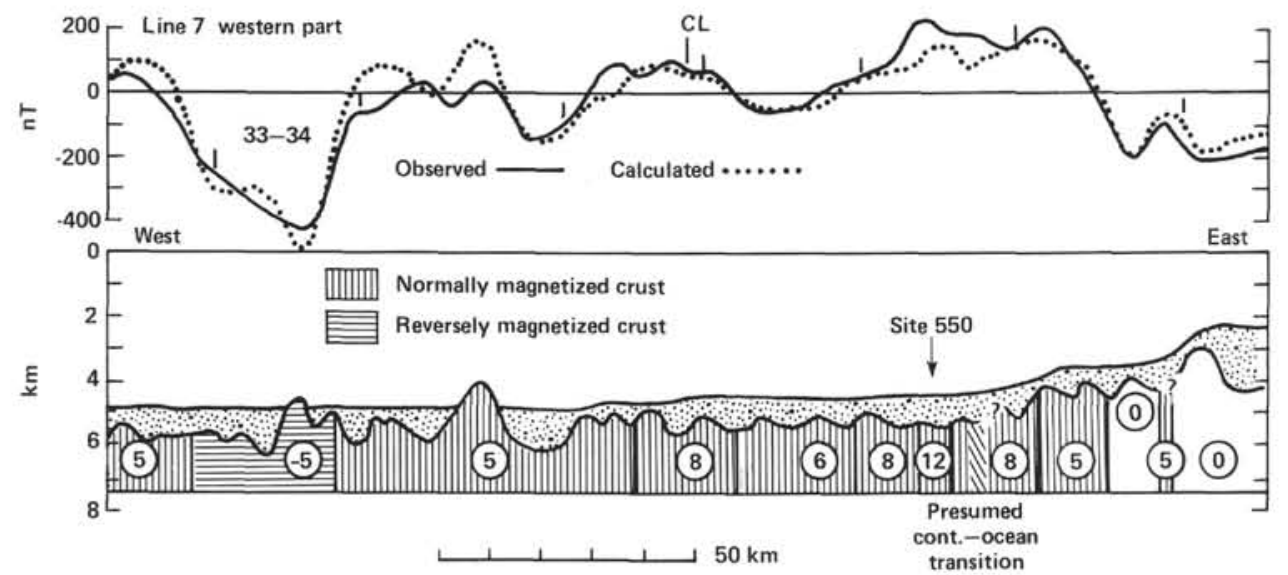

Figure 3. Detailed two-dimensional magnetic model of the western half of line 7 through Site 550, showing that normally magnetized ocean crust probably occurs between the continent-ocean transition and the deep negative anomaly identified as 33-34. Numbers encircled indicate magnetization (positive, normal; negative, reversed) in $\mathrm{A} / \mathrm{m}$, which must vary to match the calculated and observed profiles, taking topography of the magnetized layer into account. Magnetized rocks occur well east of the presumed continent-ocean transition. Ticks on profiles at 3-hr. intervals can be keyed to Figures 1 and 2 .

theless, there are details of interest. It is interesting that there is a change of strike in Anomaly 33-34 from N-S to NNW-SSE at about $48.5^{\circ} \mathrm{N}$ (Fig. 10), and that this is repeated in the anomalies and oceanic basement topography (Fig. 11) eastward, "back" toward the COT. North of the change there is good parallelism between the COT and ocean crustal trends, but south of the change the two trends diverge. This again raises the possibility of a more westerly position for the COT south of $48.5^{\circ} \mathrm{N}$, in order to maintain the parallelism. Alternatively, the divergence may reflect early asymmetrical spreading or even the shape of a northward-propagating basalt-filled crack at the time of the Bay of Biscay's first opening, which was in the Aptian, just before the onset of spreading off Goban Spur.
To solve some of the problems raised in this chapter, equally detailed data coverage and interpretation are required for the conjugate Atlantic margin off Flemish Cap. At present these are not available; in Srivastava's (1978) figure 6, for example, there is only one magnetic profile of the relevant area. These latitudes present a good opportunity to study the structure of the North Atlantic rift immediately before the onset of seafloor spreading, and efforts should be made to acquire the relevant data off Flemish Cap.

\section{ACKNOWLEDGMENTS}

The data were acquired with the invaluable help of the master, officers, and crew of the Shackleton, and the staff of the NERC Research Vessel Base, under NERC grant GR3/2712. Reviews of the 
manuscript by J. C. Sibuet, E. J. W. Jones, P. C. de Graciansky, and D. G. Masson have been most helpful.

\section{REFERENCES}

Dingle, R. V., and Scrutton, R. A., 1977. Continental margin fault patterns mapped southwest of Ireland. Nature, 268:720-722.

1979. Sedimentary succession and tectonic history of a marginal plateau (Goban Spur, southwest of Ireland). Mar. Geol., 33: 45-69.

Harrison, C. G. A., 1981. Magnetism of the oceanic crust. In Emiliani, C. (Ed.), The Oceanic Lithosphere: New York (Wiley-Interscience), pp. 219-239.
Kristoffersen, Y., 1978. Sea-floor spreading and the early opening of the North Atlantic. Earth Planet. Sci. Lett., 38:273-290.

Scrutton, R. A., 1979. Structure of the crust and upper mantle at Goban Spur, southwest of the British Isles-some implications for margin studies. Tectonophysics, 59:201-215.

Srivastava, S. P., 1978. Evolution of the Labrador Sea and its bearing on the early evolution of the North Atlantic. Geophys. J. R. Astron. Soc., 52:313-357.

Date of Initial Receipt: December 6, 1982 Date of Acceptance: May 2, 1983
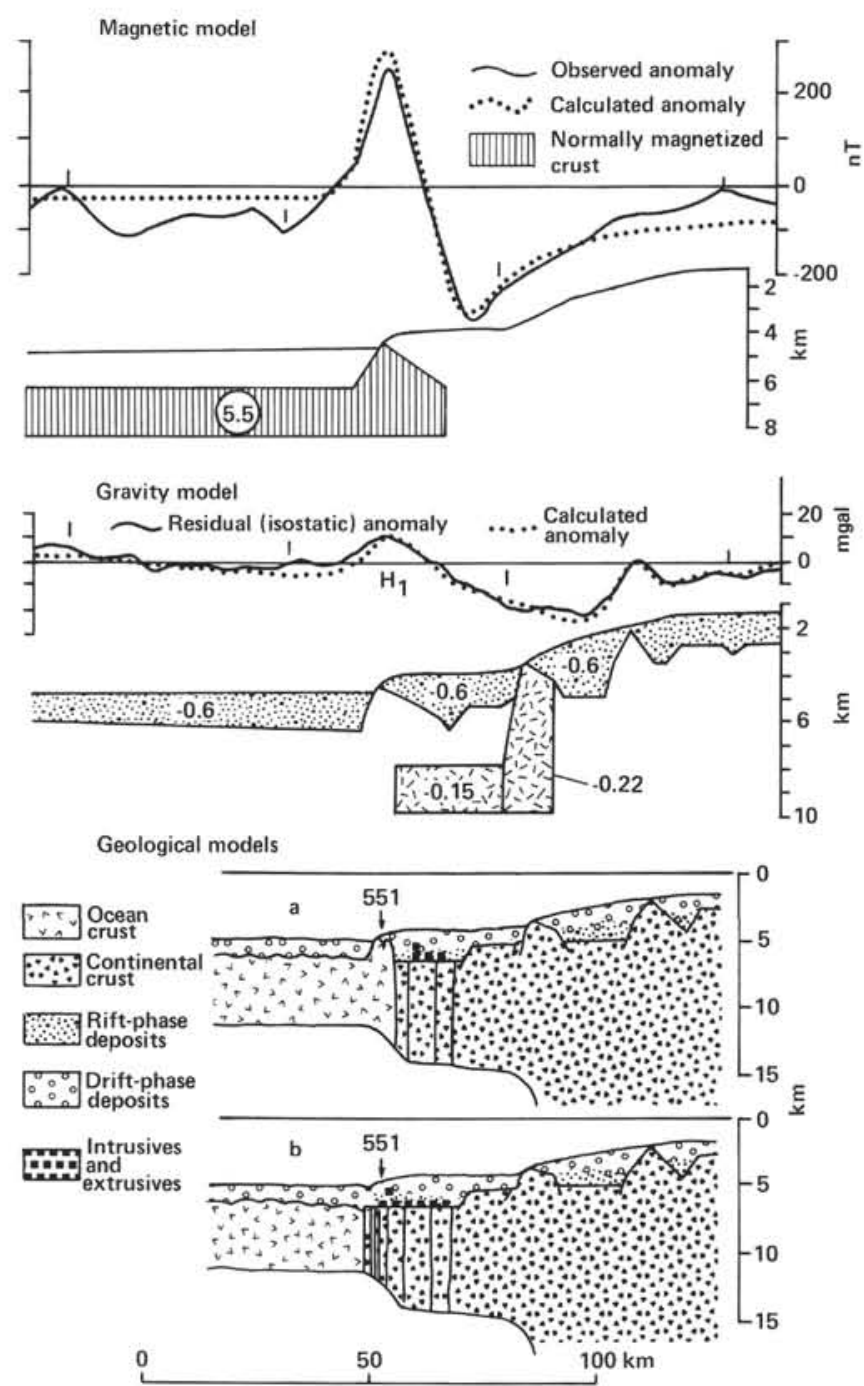

Figure 4. Magnetic, gravity, and geological models of the western half of line 6, redrawn from Scrutton (1979). The encircled value on the magnetic model is magnetization in $\mathrm{A} / \mathrm{m}$. The values on the gravity model are density contrasts in $\mathrm{Mg} / \mathrm{m}^{3}$. Ticks on the profiles are at 3-hr. intervals, and can be keyed to Figures 1 and 2. The geological models were also based on seismic reflection and refraction data. Notice the prediction of basic igneous rocks at shallow depth at Site 551 (model a), now confirmed, and the ambiguity in siting the continent-ocean transition. Model $b$ is presumed to represent the case in this study. 

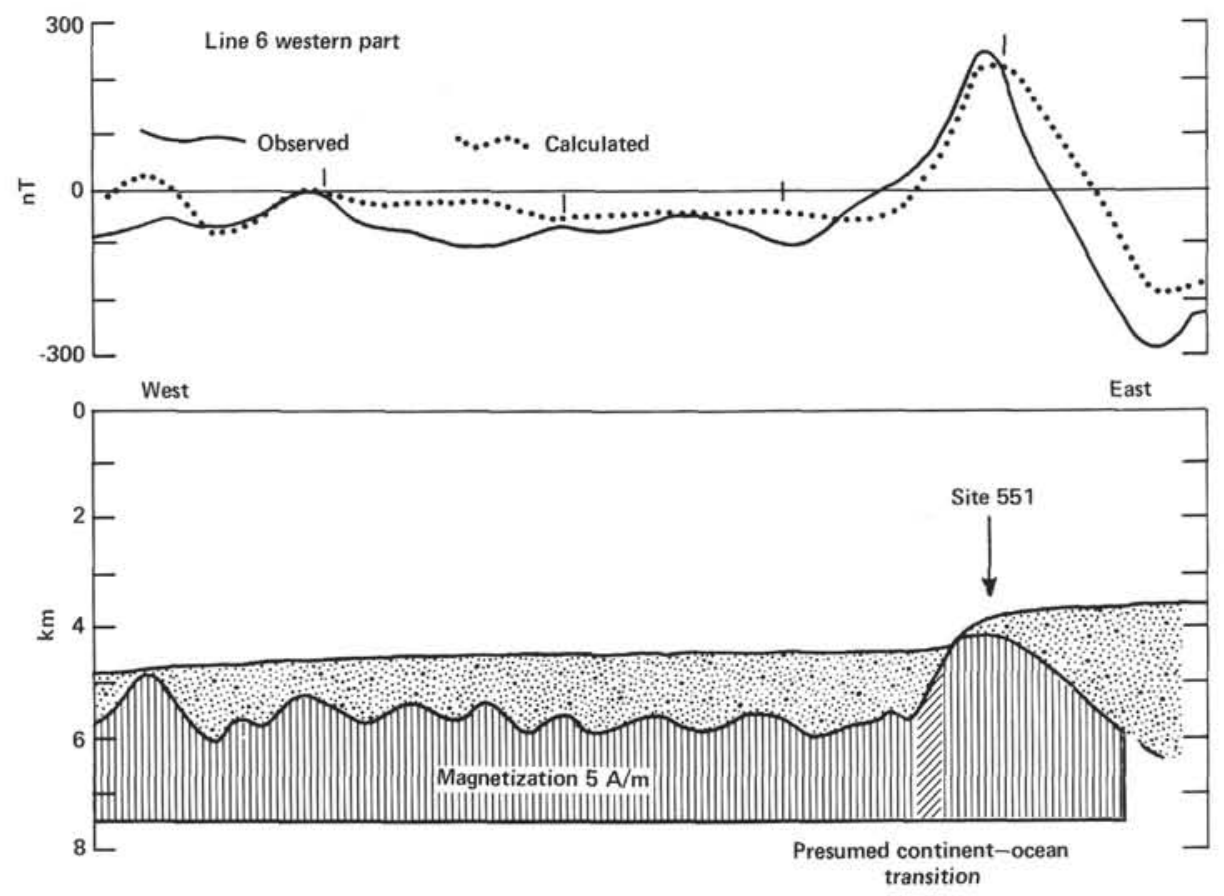

$\downarrow 50 \mathrm{~km}$

Figure 5. New two-dimensional magnetic model of the western half of line 6, constructed to confirm that the amplitude and wavelength of the small anomalies west of the continent-ocean transition could result from topography of the magnetized layer (minor variations in magnetization may also occur). The layer is entirely normally magnetized, with a mid-Cretaceous vector of strength $5 \mathrm{~A} / \mathrm{m}$. Ticks on profiles at 3-hr. intervals. Legend as in Figure 4.

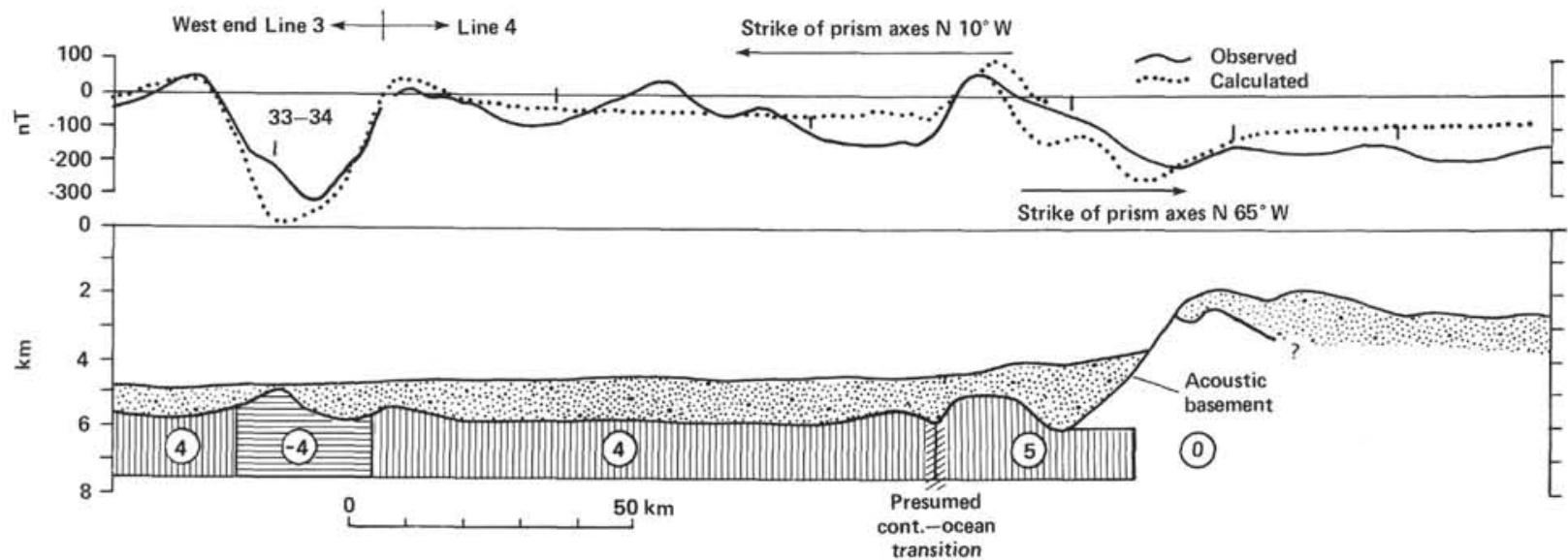

Figure 6. Two-dimensional magnetic model of line 4 extended westward to Anomaly 33-34 by using line 3. Encircled numbers give magnetizations in $\mathrm{A} / \mathrm{m}$ (positive, normal; negative, reversed), and show that normally magnetized ocean crust probably occurs between the continent-ocean transition and Anomaly 33-34. Magnetized rocks occur well east of the presumed continent-ocean transition, as on lines 6 (Figs. 4 and 5) and 7 (Fig. 3). Since there is a change in the strike of line 4 at about midway, the calculated profile has been derived in two parts that overlap slightly. Ticks on the profiles at 3-hr. intervals. Legend as in Figures 3 and 4. 


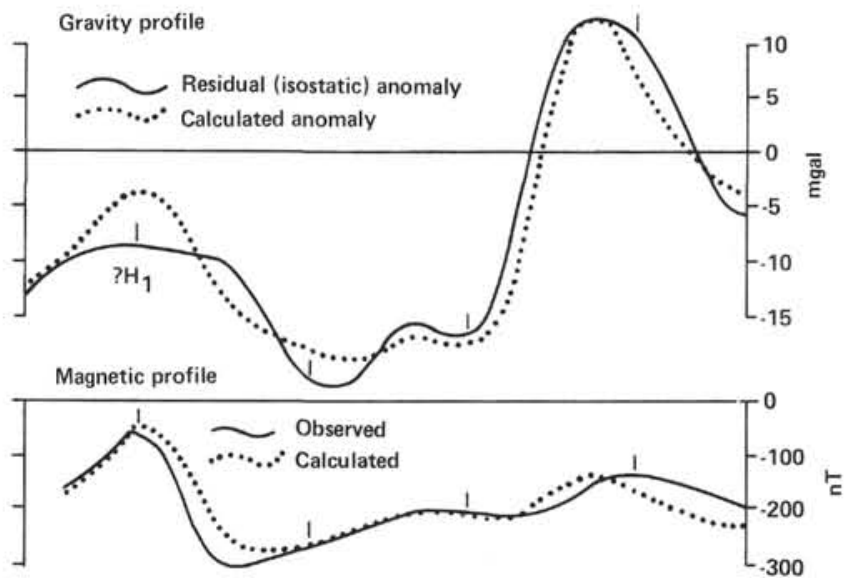

Geological model
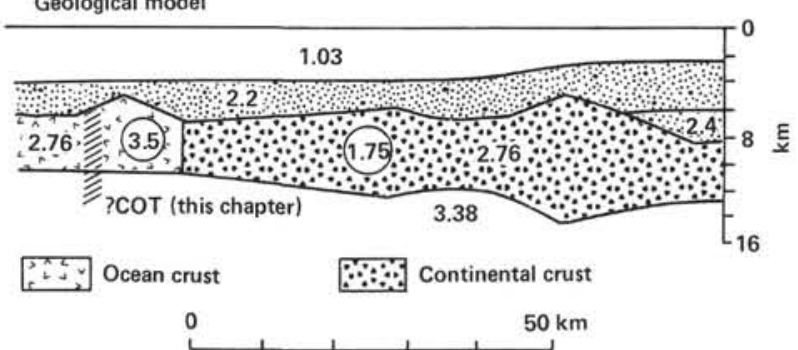

Figure 7. Gravity, magnetic, and geological models of the eastern half of line 1, as deduced by J. B. Megson (pers. comm., 1983). Encircled values on the model are normal magnetizations in $\mathrm{A} / \mathrm{m}$. The other values are densities in $\mathrm{Mg} / \mathrm{m}^{3}$. Ticks on the profiles are at 3-hr. intervals. ?COT marks the location of the continent-ocean transition presumed in this chapter, on the opposite side of a basement high from the location deduced by Megson. 


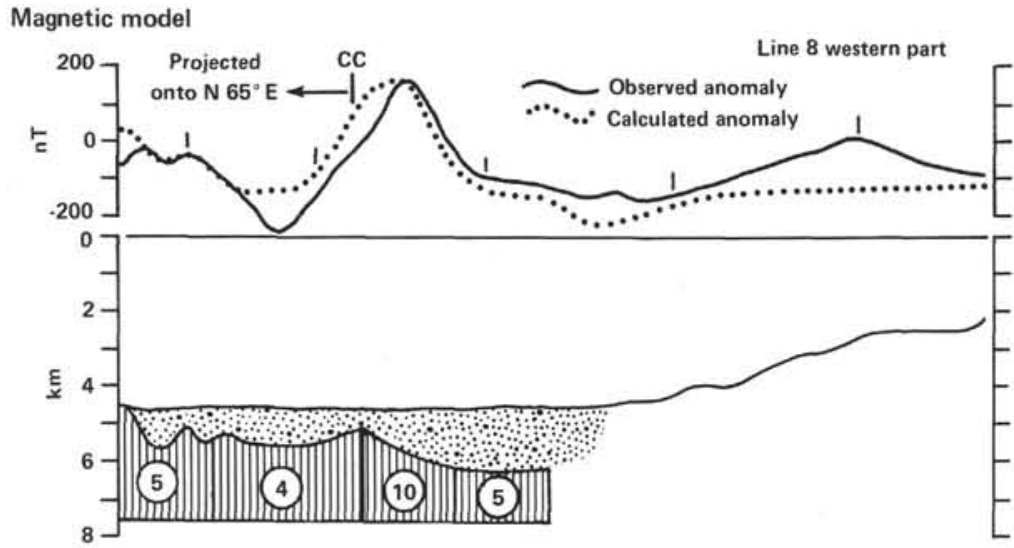

Gravity model

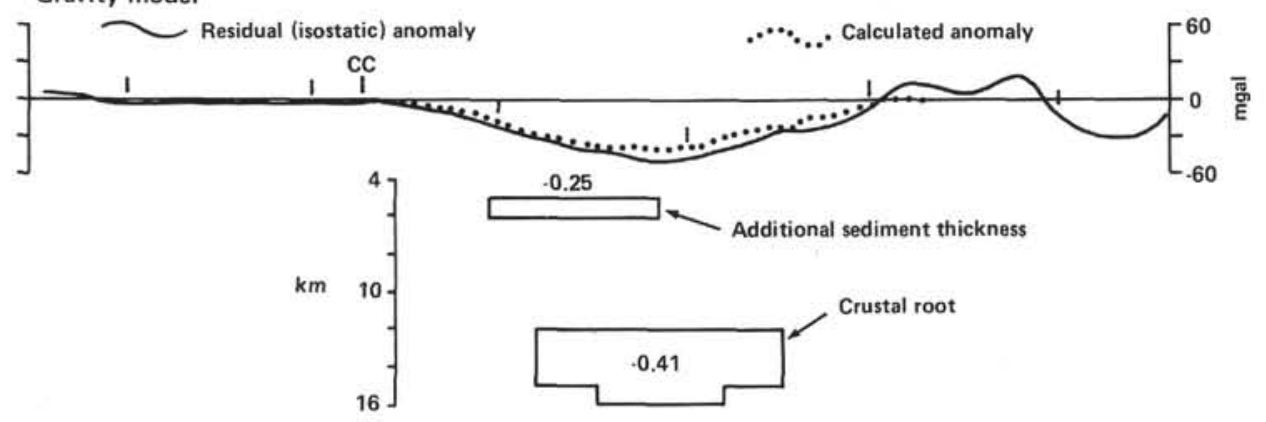

Geological model

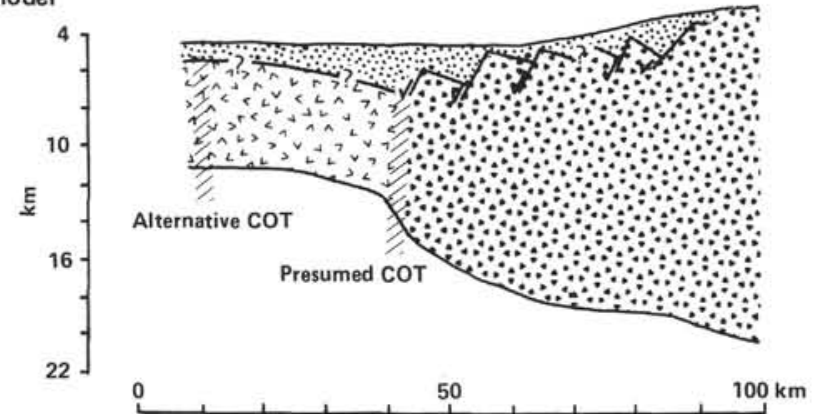

Figure 8. Magnetic, gravity, and geological models of the western part of line 8 . The magnetic model gives magnetizations, all normal mid-Cretaceous vectors, in $\mathrm{A} / \mathrm{m}$ (encircled). If the magnetized layer is all ocean crust, then the continent-ocean transition is correctly located. The gravity model is based on the isostatic anomaly remaining after removal of the effect of a three-dimensional isostatic model of the crust. Low $\mathrm{L}_{2}$ is caused partly by a three-dimensional sediment thickening and partly by a three-dimensional crustal root. Values on the models are density contrasts in $\mathrm{Mg} / \mathrm{m}^{3}$. The geological model suggests that the crust in the vicinity of the continent-ocean transition is depressed out of isostatic equilibrium relative to surrounding areas. Legend as in Figure 4. 


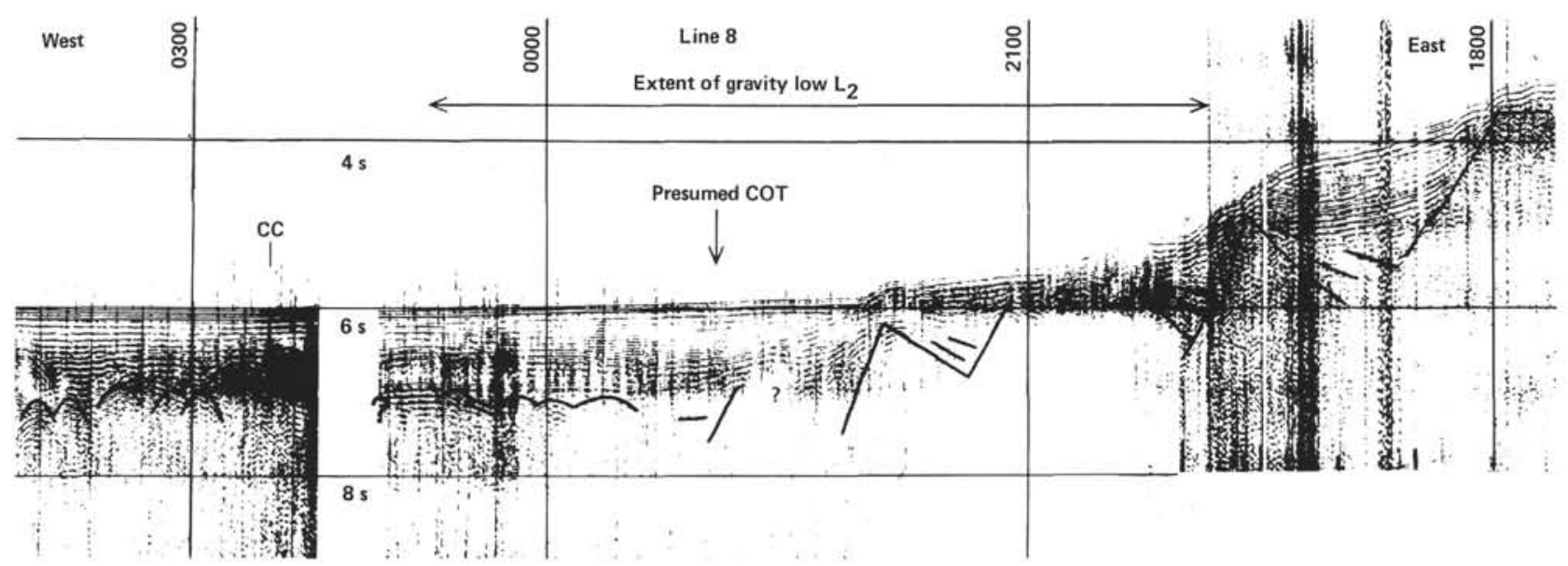

Figure 9. Edinburgh seismic reflection profile along line 8 in the vicinity of gravity low $L_{2}$. Three-hour time lines and 2-s two-way travel time scale lines shown. Acoustic basement is highlighted-west of the course change it is typically oceanic, and east of about 2200 it is typically continental. Between these points the position of the transition is assumed, on the basis of a projection from its preferred position on tracks to the north, but its position is not clear on this record. However, see Figure 8.

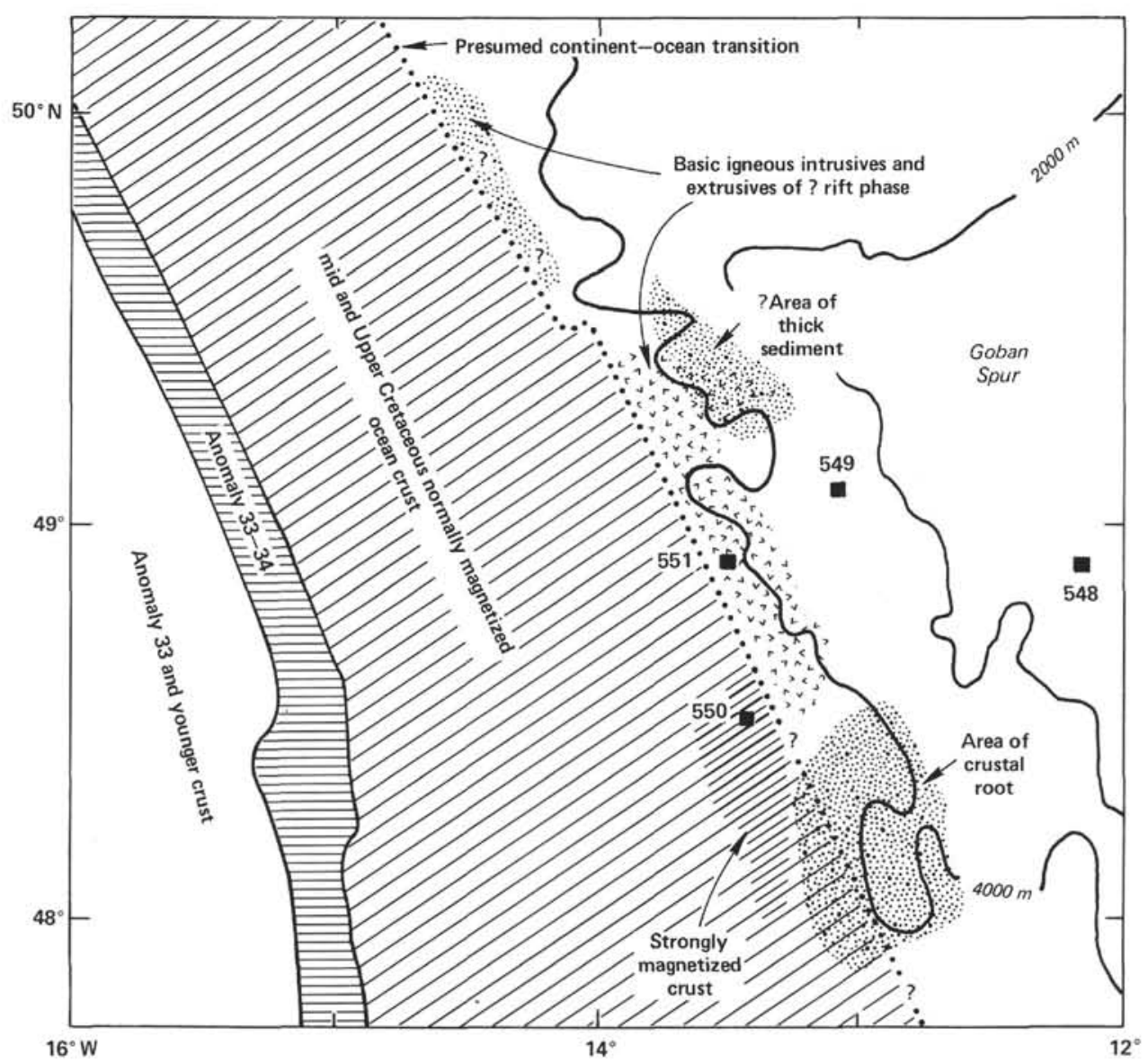

Figure 10. Summary of features inferred from magnetic and gravity modeling with respect to IPOD drill sites and the presumed location of the continent-ocean transition. 


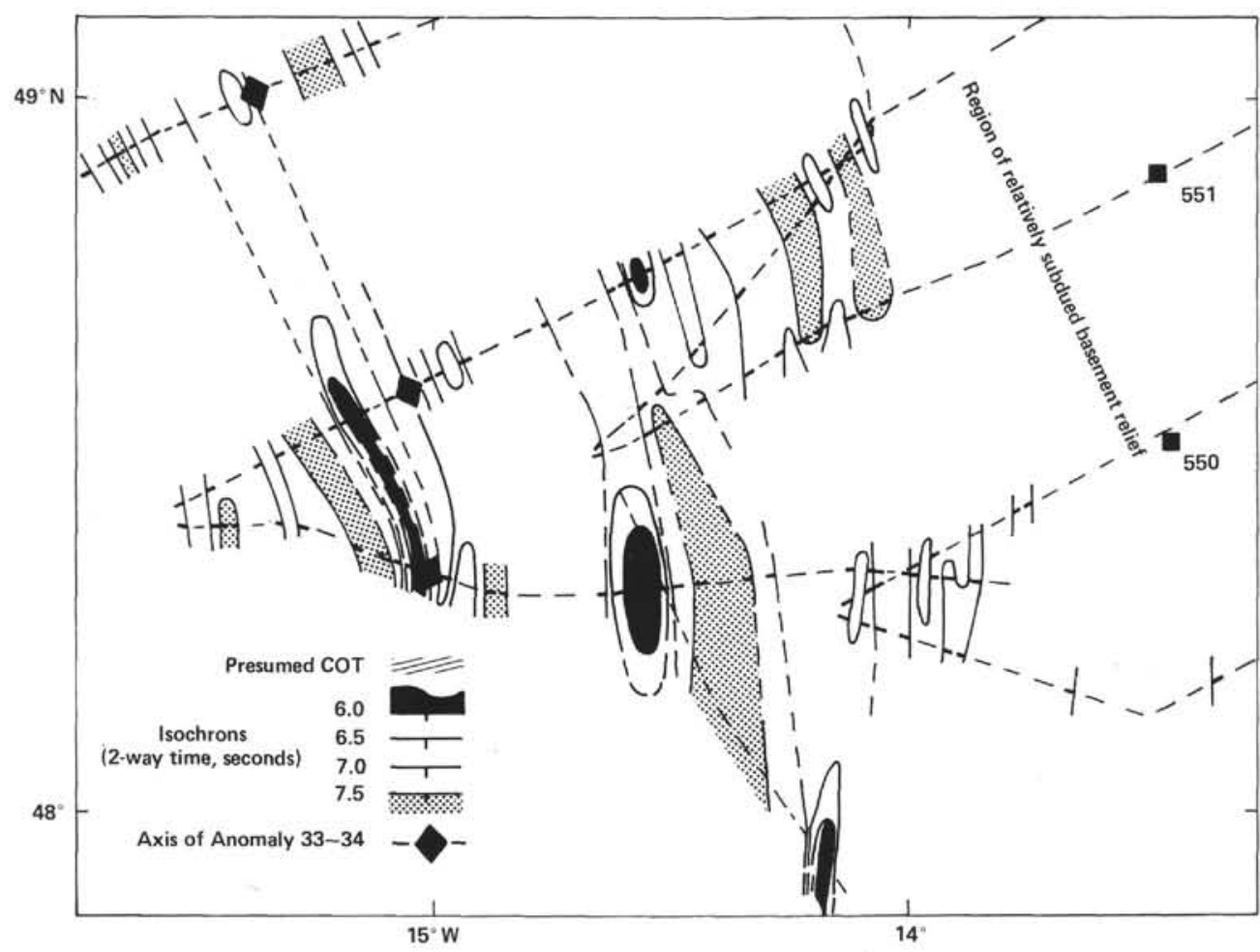

Figure 11. Depth to acoustic basement on Edinburgh seismic reflection profiles between Site 550 and Anomaly 33-34. Notice the change in strike of basement structures (which is reflected in the magnetic anomalies, figure 18, Masson et al., this volume), from WNW-ESE to N-S in the south of the area. 